\title{
NAVOCEANO Survey 2010 Vision and Reality....How Close Are They?
}

\author{
Barbara Reed, Bill Elenbaas, Gail Smith, Laurie McCosh, Rob Wahl, Terry Duvieilh, and Mel Wagstaff \\ Naval Oceanographic Office \\ 1002 Balch Blvd. \\ Stennis Space Center, MS 39522 USA
}

\begin{abstract}
This paper compares the vision created in 1998 of the predicted future of Naval Oceanographic Office surveys in 2010 with the actual implementations of the technology in 2010. This paper explores several technology areas (communication, autonomous vehicles, airborne oceanography, hydrography/bathymetry, physical oceanography, and acoustics) examined while envisioning the future of Navy ocean surveys in 1998 and compares the predictions to the realities of today.
\end{abstract}

\section{INTRODUCTION}

We do not often get the opportunity to reflect on the vision of the past and compare it to the reality of the present. The authors of this paper are the remaining individuals at the Naval Oceanographic Office (NAVOCEANO) who were part of a team chartered in 1998 to "...provide a brief review of the direction of technology and an initial cut at how these changes could be implemented to fundamentally change the way NAVOCEANO conducts survey operations by the year 2010." Since we are currently in the prediction year of 2010, it is not only interesting and educational to examine how well we predicted the use of technology in ocean surveys, but it can also help guide how we try to predict and plan for the next decade and beyond. The team was led by then CDR Dave McCarren and produced "Survey 2010 - a NAVO Vision" [1]. A follow-on document, "Naval Oceanographic Office Ocean Survey 2010" [2], was presented by then Commanding Officer CAPT Larry Warrenfeltz at the Ocean Community Conference in 1998.

After reviewing Commander, Naval Meteorology and Oceanography Command (CNMOC), Navy, and Joint Strategic publications, the team's takeaway was that the Navy's mission for the foreseeable future was "expected to remain focused on regional conflicts in the littoral and one of the keys to battlefield dominance will be information superiority." (Not much has changed there, either!) The "Littoral" was defined as areas where the physical characteristics of the water mass are highly variable and the acoustic paths for weapons and sensors are dominated by the effects of the bottom (i.e., shallow water) or anything shallower than 1000 meters water depth. The assumptions were:

* increased role of remote sensing to support and supplant shipboard surveys,

* increased airborne surveys,

* required data elements similar to current requirements,

* eight ships - six hydrographic survey launch (HSL) equipped,

* increasing reliance on autonomous vehicles (including airborne, underwater and buoys), and

* a continued and growing importance of acoustic imagery.

The team was encouraged to "...think with a true vision of the capabilities twelve years in the future, with a NAVOCEANO corporate view..."

While some of the assumptions have changed - primarily due to financial constraints (i.e., we now only have six ships (three HSL equipped); the number of Navy airborne lidar surveys has increased, but airborne deployment of buoys has been cut) many of the assumptions are the same, and much of the prominent strategic guidance remains the same.

\section{TECHNICAL AREAS CONSIDERED IN VISION}

Let's walk through some of the technical areas that were considered and examine the status: 
TABLE I

Comparison of Technical AReas' State In 1998, the Projected State for 2010, AND the Actual State for 2010

\begin{tabular}{|c|c|c|c|}
\hline Technical Area & Then & Vision for 2010 & Actual for 2010 \\
\hline Communications & $\begin{array}{l}\text { - } 9.6 \mathrm{~Kb} \text { on demand } \\
\text { - }<1 \mathrm{hr} / \text { day }\end{array}$ & - $1 \mathrm{mb}$ continuous & $\begin{array}{l}\text { - Normally } 1.024 \mathrm{Mb} / \mathrm{sec} \text { ship to shore continuous on } 6 \text { ships } \\
\text { deployed globally } \\
\text { - Shore to ship used for system configuration and } \\
\text { troubleshooting }\end{array}$ \\
\hline $\begin{array}{l}\text { Autonomous } \\
\text { Underwater } \\
\text { Vehicles (AUVs) }\end{array}$ & $\begin{array}{l}\text { - } 1 \text { large ( }>5 \text { ton) high-cost } \\
\text { vehicle }\end{array}$ & $\begin{array}{l}\text { - Many miniature, low-cost, } \\
\text { long-endurance vehicles } \\
\text { - } 6 \text { month endurance } \\
\text { - Satellite reporting }\end{array}$ & $\begin{array}{l}\text { - } 14 \text { passive propulsion gliders ( } \sim 150 \text { by } 2015) ; \sim 0.5 \mathrm{kts}, 1-6 \\
\text { month duration, } 200-1000 \text { mmaximum depth; sensors } \\
\text { include CTD + optics; all transmit data daily to Glider } \\
\text { Operations Center (GOC) } \\
\text { - } 7 \text { active propulsion vehicles, } \sim 4 \mathrm{kts}, 16-40 \text { hour duration, } 100 \\
-6000 \text { m maximum depth; sensors include multibeam, side } \\
\text { scan, and forward looking sonars, sub-bottom profilers, digital } \\
\text { still cameras, ADCPs, CTDs, and optical backscatter } \\
\text { - Not only satellite reporting, but remote control through use of } \\
\text { gliders through the GOC }\end{array}$ \\
\hline Airborne & $\begin{array}{l}\text { - No lidar sensor } \\
\text { - Synoptic observations of } \\
\text { ambient noise, } \\
\text { transmission loss (TL) } \\
\text { water profiles }\end{array}$ & $\begin{array}{l}\text { - New Lidar sensor deployable } \\
\text { on Unmanned Airborne } \\
\text { Vehicle (UAV) } \\
\text { - Over the Horizon (OTH) links } \\
\text { for data transfer } \\
\text { - Auto-reporting buoys and } \\
\text { moorings }\end{array}$ & $\begin{array}{l}\text { - } 3 \mathrm{kHz} \text { airborne bathymetric lidar; } 20 \mathrm{kHz} \text { topographic lidar, } \\
\text { hyperspectral imager, digital camera } \\
\text { - Network data transfer of subsets of data from field operations } \\
\text { - Auto reporting GPS buoy } \\
\text { - No airborne buoy or acoustics program }\end{array}$ \\
\hline $\begin{array}{l}\text { Hydrography/ } \\
\text { Bathymetry }\end{array}$ & $\begin{array}{l}\text { - Multibeam on ships, single } \\
\text { beam on HSLs } \\
\text { - Shore-based tide gages } \\
\text { - Analog side scan sonar } \\
\text { - Low collection-processing } \\
\text { ratio }\end{array}$ & $\begin{array}{l}\text { - Backscatter from all } \\
\text { multibeam and side scan } \\
\text { sonar } \\
\text { - Bottom-mounted tide gages } \\
\text { - High collection-processing } \\
\text { ratio } \\
\text { - Comm pipe allows } 2 \text { person } \\
\text { reduction in survey crew } \\
\text { - } 5-8 \text { simultaneous surveys } \\
\text { supported by the Survey } \\
\text { Operations Center (SOC) }\end{array}$ & $\begin{array}{l}\text { - Multibeam and backscatter on ships and HSLs } \\
\text { - Digital side scan sonar on ships and HSLs } \\
\text { - MB and digital SSS on AUV } \\
\text { - High collection-processing ratio } \\
\text { - Satellite-linked tide gages, expendable tide gages, ERS } \\
\text { - Non-traditional bathymetry data sources (jet ski, expeditionary } \\
\text { teams, satellite derived) } \\
\text { - Multibeam data downloaded from } 6 \text { simultaneous surveys via } \\
\text { SOC and quality controlled daily } \\
\text { - High resolution and accuracy mapping; enormous data } \\
\text { volumes }\end{array}$ \\
\hline $\begin{array}{l}\text { Physical } \\
\text { Oceanography } \\
\text { (PhysO) }\end{array}$ & $\begin{array}{l}\text { - Ship sensing using CTDs, } \\
\text { XBTs } \\
\text { - Drifting buoys deployed } \\
\text { from aircraft } \\
\text { - Moorings }\end{array}$ & $\begin{array}{l}\text { - } \text { AUV w/OTH reporting } \\
\text { - UAVs/buoys } \\
\text { - Buoys } \\
\text { - Overhead remote sensing } \\
\text { - Fusion Center at } \\
\text { NAVOCEANO } \\
\end{array}$ & $\begin{array}{l}\text { - } 14 \text { AUVs with PhysO sensors, expanding to } \sim 150 \\
\text { - GOC controlling AUVs } \\
\text { - More efficient handling of satellite observations } \\
\text { - Coastal monitoring buoys } \\
\text { - Enhanced optics collection and processing capabilities }\end{array}$ \\
\hline
\end{tabular}

\section{A. Communication}

The communication vision and reality line up well. In 1998, satellite-based telecommunications to and from the T-AGS ships were largely limited to administrative correspondence. Transfer of survey data was limited to $9.6 \mathrm{~kb}$ per second and was available only about an hour a day. Crews performed proof-of-concept data transmissions for most data types, but the standard procedure was to mail or hand carry digital data to Stennis Space Center from a ship's inport location.

Today, the ships employ continuous C-band satellite service capable of transmitting more than $1 \mathrm{Mb}$ per second from ship to shore. The system now in place can transfer as much as 12 gigabytes per day, and the T-AGS vessels routinely transmit around 10 gigabytes per day. Although the increase in capacity has been considerable, not all data can be sent via satellite. Large raw (unprocessed) data files and certain data types, for which file size is normally very large (such as acoustic backscatter and sub-bottom profile data) are not routinely sent back via satellite. But most processed data are transmitted via

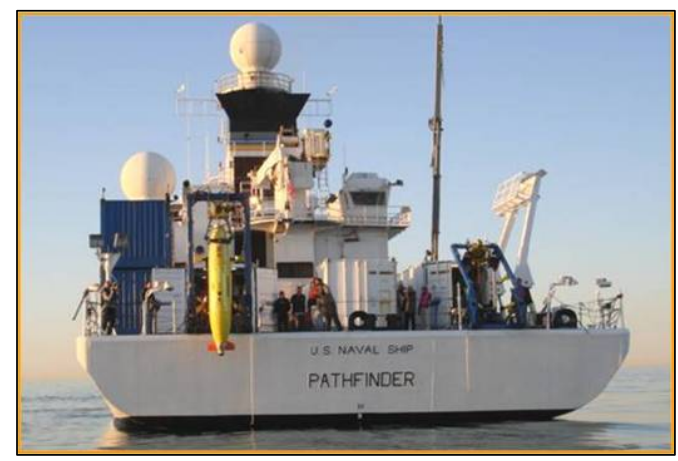

Fig. 1 View of various equipment from the stern of the USNS Pathfinder 
satellite, allowing for shorter production timelines and better survey monitoring. Automated software routines guarantee the integrity of the received files.

Near-term plans include improvements to transmission procedures that will increase the efficiency of file transfers. These improvements will enable more data to be transmitted without increasing bandwidth.

\section{B. Autonomous Underwater Vehicles $(A U V S)$}

AUVs are probably the area that we have expanded the most over the last ten years. We currently deploy a variety of vehicles with a wide array of capabilities using both active and passive means of propulsion. In addition to the vehicles we are already using, a large number of additional vehicles are in various stages of procurement. We have established a Glider Operations Center (GOC) to facilitate control and data transfer from our glider vehicles. We have logged a total of more than 23,000

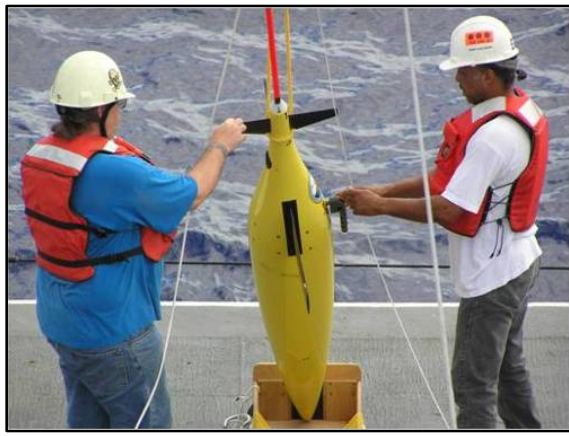

Fig. 2 NAVO personnel deploying a Seaglider nautical miles on several classes of active propulsion AUVs that have depth capabilities from shallow water to 6,000 meters and that employ a wide variety of sensor packages. We have integrated AUV launch and recovery systems onto our six T-AGS 60 class ships and currently have a new ship under construction (T-AGS 66) that will include several enhancements for AUV support.

We currently operate 14 glider vehicles that are capable of navigating in 3-D ocean space by means of a passive propulsion system that uses variable buoyancy and weight distribution to steer the vehicles on a controlled descent in the desired direction of travel. On reaching a pre-determined depth, the vehicles re-adjust their buoyancy and weight distribution to ascend to the surface, again moving in the desired direction of travel. We currently have two depth variants of glider, shallow and deep. The shallow version has a 200 meter depth capability, and the deep 1000 meters. Each glider has a Sea-Bird Conductivity, Temperature, and Depth (CTD) profiler, WET Labs optics sensor, attitude sensor, Global Positioning System (GPS), and an Iridium satellite modem for data telemetry when surfaced. In addition to the data provided directly by these sensors, the gliders can also estimate depth-averaged currents from GPS and attitude data. The shallow water gliders have an endurance of about one month, and the deep water gliders, four to six months. The glider operates by using the Iridium modem to call into computers at the NAVOCEANO GOC where command, target, and science files are created by glider pilots to tell the glider how deep to dive, how many dives to make before calling in, which Lat and Lon to swim toward, and when to use the CTD and optics sensors (i.e., turn off after a certain depth or how often to take a sample). The gliders are capable of forward speeds of up to 0.5 knot during descent and ascent. When the glider calls in to the GOC, all data collected are transferred, and the glider will download any awaiting command, target, and science files. With the command files, the pilots can also optimize the glider by adjusting the center of balance for pitch, roll, and buoyancy. The gliders fly in a saw tooth pattern and use dead reckoning while underwater. Gliders can be completely autonomous with the pilots monitoring their status when the glider calls in or can be reprogrammed for destination, depth, and sensor use on the fly to meet real-time mission needs. The gliders we currently operate are from the University of Washington, Teledyne Webb Research, and Scripps Institution of Oceanography. Last year, Teledyne Brown Engineering/Teledyne Webb Research was awarded the Navy contract to provide gliders. The gliders purchased under this contract will have an endurance of about 140 days, and the contract has options for up to 150 glider vehicles.

We currently own seven active propulsion Remote Environmental Monitoring Units (REMUS) AUVs; three with 6,000 meter depth capability, two with 2,500 meter depth capability, one with 600 meter depth capability, and one with 100 meter depth capability. The vehicles are outfitted with a wide variety of sensors, some of which are modular to allow optimizing the vehicles to a particular mission. All vehicles currently use rechargeable Lithium-Ion battery packs as their power source. The vehicles are typically programmed to run a pre-determined navigation pattern over an entire sortie but can be redirected while submerged via an acoustic modem should the need arise. Sub-surface navigation is provided by inertial and long baseline acoustic positioning systems. The vehicles are also outfitted with GPS, Iridium satellite modems, and WI-FI data communication systems for use when surfaced.

The 6,000 meter depth capable vehicles have a 28 inch body diameter, are slightly more than 12 feet in length, and weigh approximately $1900 \mathrm{lbs}$. They have a 65 nautical mile range at 4 knots over a typical 16 to 18 hour sortie. The vehicles are outfitted with Edge-Tech $120 / 410$ or 300/600 kHz side scan sonars, digital still cameras, Imagenex forward looking sonars, Omni Technologies $30 \mathrm{kHz}$ subbottom profilers, Teledyne-RD Instruments Acoustic Doppler Current Profiler (ADCP) systems, SeaBird CTD systems, WET Labs optical backscatter sensor, and inertial navigation systems. One vehicle has an Imagenex multi-beam sonar used for gap-filling the side scan imagery directly beneath the vehicle.

The 2,500 meter depth vehicles have 14 inch diameter body, are just less than 14 feet in length and weigh approximately $800 \mathrm{lbs}$. They are capable of covering approximately 160 nautical miles at 4

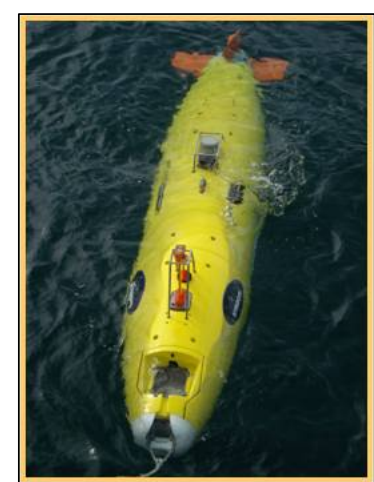

Fig. 3 NAVO's REMUS 6000 in the water 
knots, with typical deployments of up to 40 hours duration. They are equipped with an EdgeTech $850 \mathrm{kHz}$ dynamically focused side scan sonar, digital still camera with LED lighting, Teledyne-RD Instruments ADCP, Omni Technologies $200 \mathrm{kHz}$ parametric sub-bottom profiler, Neil Brown Ocean Sensors, Inc. (NBOSI) CTD, and WET Labs optical backscatter sensors.

The 600 meter depth vehicle has a 12 inch diameter body, is just under 14 feet in length, and weighs approximately $700 \mathrm{lbs}$. It has 25 hour endurance and can cover approximately 100 nautical miles at 4 knots. It is equipped with a Kongsberg EM-3002 multibeam sonar, EdgeTech dynamically focused $850 \mathrm{kHz}$ side scan sonar, Imagenex forward-looking sonar, TeledyneRD Instruments $600 \mathrm{kHz}$ ADCP, NBOSI CTD, and WET Labs optical backscatter sensor.

As demonstrated by the number and variety of AUV platforms currently being deployed by NAVOCEANO, we have come a long way toward realizing many of the AUV-related goals envisioned in "Survey 2010 - A NAVO Vision." While we do not currently operate using any of the autonomous docking-station scenarios described in the paper, such methods are being conceptualized, particularly for use with the moon pool-equipped T-AGS 66 vessel now under construction.

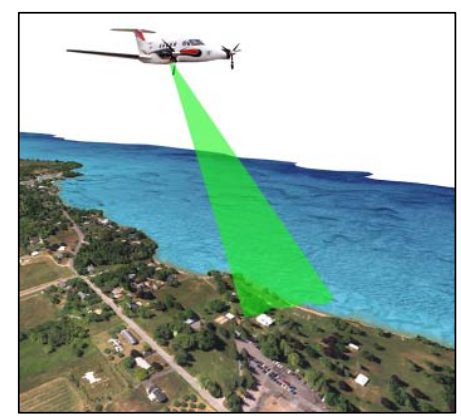

Fig. 4 Depiction of CHARTS aircraft surveying with Lidar

\section{Airborne}

The Navy's participation in the airborne drifting buoy and acoustics programs has recently been cut due to financial constraints, but NAVOCEANO continues to operate airborne coastal survey sensors.

In 1998, NAVOCEANO was using a first-generation Scanning Hydrographic Operational Airborne Lidar System (SHOALS) sensor owned and operated by the US Army Corps of Engineers (USACE), operating at a pulse repetition rate of $200 \mathrm{~Hz}$. Keeping in step with improvements in laser technology, the SHOALS sensor underwent a series of upgrades, increasing the firing rate (to $400 \mathrm{~Hz}$ in 1999 and $1000 \mathrm{~Hz}$ in 2003) and replacing the down-looking digital video camera with a $1 \mathrm{~Hz}$ digital color imager. In 2005, the Navy accepted delivery of the Compact Hydrographic Airborne Rapid Total Survey System (CHARTS) as a life cycle replacement for the SHOALS sensor. As delivered, the CHARTS sensor included $3000 \mathrm{~Hz}$ hydrographic and $20,000 \mathrm{~Hz}$ topographic lidars, a $1 \mathrm{~Hz}$ RGB camera, and a CASI-1500 hyperspectral imager. Simultaneous spectral and lidar data collection provides the capability of classifying land and sub-surface features through active sensor (lidar) and passive sensor (hyperspectral imager) data fusion. A high-resolution, photogrammetric quality Applanix DSS320 digital camera was added to the CHARTS sensor suite in 2010 .

The CHARTS system is currently installed on a commercial Beecheraft King Air B200 aircraft operated by Kenn Borek Air of Calgary, Alberta, Canada and staffed with survey personnel from Northrop Grumman and NAVOCEANO personnel based at the Joint Airborne Lidar Bathymetry Technical Center of Expertise (JALBTCX) located at Stennis International Airport in Kiln, Mississippi. This fusion of government and contractor personnel makes for an efficient, flexible data collection capability.

Still one of only a handful of hydrographic lidar systems in the world, the CHARTS system is operated by NAVOCEANO along with the USACE and the National Oceanic and Atmospheric Administration (NOAA), partners in the JALBTCX. The CHARTS sensor suite represents a coastal charting tool able to meet both International Hydrographic Organization Order 1a and USACE Class 1 specifications for depth measurement and coastline positioning requirements.

In FY2010, NAVOCEANO completed its most productive airborne survey season ever, collecting over $900 \mathrm{~nm}^{2}$ of survey data in three theaters in less than eight months (USPACOM, USSOUTHCOM, USCENTCOM), including a rapid deployment as part of Operation Unified Response following the 12 January 2010 earthquake in the Republic of Haiti.

Employing lidar technology on an Unmanned Airborne Vehicle (UAV) had been planned since the late 1990s but was postponed due to resource constraints. There has been recent activity to procure lidar- and spectral-capable UAVs for a variety of uses including Coastal Navigation, Nautical Charting, Military Rapid Environmental Assessment, Regional Coastal Zone Mapping, Emergency Response/Disaster Recovery, and Environmental Conservancy.

\section{Hydrography/Bathymetry}

Two evolutions of new multibeam sonars on the ships and HSLs have passed since the original document, significantly advancing the seafloor mapping capability in support of safe navigation, Anti-Submarine Warfare, Expeditionary Warfare, and Mine Warfare. All NAVOCEANO ships are equipped with both shallow and deep water high-resolution multibeam sonars, and four of six survey ships have been upgraded to obtain even higher resolution and greater efficiency with more than 400 beams per swath and dual swath capability. These systems are mounted on a gondola to reduce noise. The new sonars allow surveying at higher ship speeds and provide enhanced

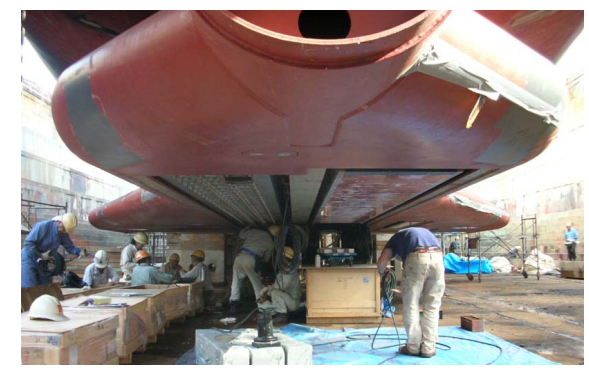

Fig. 5 Hull-mounted multibeam sonar gondola installation on USNS SUMNER 
object detection capability, eliminating the need for towing side scan sonar in some cases. All HSLs are equipped with a highresolution multibeam system as well as digital side scan sonars. The Global Acoustic Positioning System for side scan sonar allows accurate tracking of the towfish for more accurate data and has proved invaluable for towing emergencies.

Seabed backscatter imagery and water column backscatter imagery are available from all multibeam systems. Data volumes have exploded. A survey ship outfitted with two HSLs can collect $10 \mathrm{~GB} /$ day of multibeam data when all three platforms are surveying. An extra $130 \mathrm{~GB} /$ day is added if seabed and water column backscatter imagery is recorded. Both NAVOCEANO ships and HSLs are equipped with high-resolution, dual-frequency digital side scan sonar systems that add $29 \mathrm{~GB} /$ day to the data collection volume. In addition, the high-resolution multibeam sonar data acquired from the autonomous vehicles described above add to the mapping capability and data volumes.

Large multibeam data volumes have necessitated new techniques for data cleaning and review. NAVOCEANO has adopted an algorithm that creates a best-fit surface along with uncertainty values. The user is guided to suspect areas indicated by the uncertainty values for further validation and/or cleaning. This has significantly improved the collection-to-processing ratio by eliminating the need to review every data point of the raw multibeam data.

New technology for water level corrections of hydrographic data (one of the largest sources of error in a final depth value) has evolved in several ways. Operational tide gages are now equipped with Iridium modems that transmit near-real-time data to NAVOCEANO via satellite. Conventional tide gages require shore-based installation and monitoring, and force protection issues have pressured survey parties to spend less time ashore. Water level corrections can now be achieved by using GPS ellipsoid heights collected by the survey platform and ellipse-chart datum information collected by GPS buoys (ERS - Ellipsoidal Referenced Survey).

NAVOCEANO has also made great strides in incorporating non-traditional platform data into production. Bathymetry data are also collected by jet skis equipped with singlebeam sonars and digital side scan systems, expeditionary teams using portable sonar kits, and satellite-derived bathymetry.

\section{E. Physical Oceanography}

Physical Oceanographic (PhysO) data collection and processing capabilities have made significant advances since 1998. These advances have enabled NAVOCEANO to receive observed and processed data from a variety of systems in near-real-time for subsequent assimilation into and improvement of operational oceanographic models and data bases that directly support Naval operations. Physical oceanographic measurements have benefited the most from new AUV platforms and effective use of satellite sensors.

Multiple advances in sensor technologies have been integrated into our data collection/processing suites. A representative list of sensor packages in our present day inventory include (1) operational gliders with CTD and optics sensors (see AUV section); (2) dual CTD sensors on our new shipboard CTD systems vice single sensors on the earlier CTDs; (3) present-day smaller ADCPs with several frequency/depth range options, in-water acoustic communications, and real-time data transmission; (4) replacement of the T-AGS $150 \mathrm{kHz}$ ADCPs with dual $300 \mathrm{kHz}(100 \mathrm{~m})$ and $38 \mathrm{kHz}(800 \mathrm{~m})$ systems; (5) several new marine optics packages that include the micro-surface acquisition system (MicroSAS), a multispectral above-water radiometer capable of measuring remote sensing/reflectance, transmissometers that are currently integrated into NAVOCEANO's CTD collection suite, and the Mine Warfare Battlespace Profiler; (6) Underwater Bioluminescence Assessment Tool (UBAT), a compact, simple to operate, shipboard flow-through system measuring bioluminescence, which will replace the current shipboard system (BIOLITE); (7) Coastal Monitoring Buoys, which transmit meteorological observations and subsurface conductivity, temperature, pressure, currents, and turbidity by Iridium; (8) Moving Vessel Profiler (currently under testing and review), which will collect data throughout the water column continuously while being towed so profiles can be collected without stopping the ship; and (9) smaller and easier to deploy overthe-side bioluminescence packages.

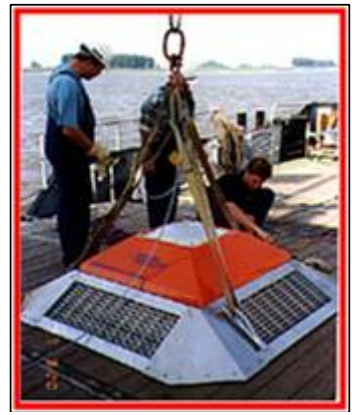

Fig. 6 Bottom-mounted ADCP in trawl-resistant mount
Advances in our processing and communication capabilities have mirrored advances in sensor technology. We've advanced from software packages capable of only processing/archiving and viewing data until surveys were completed, to present-day acquisition data loggers, which allow us to look at and process all sensor data in real-time. Advances in expendable sensor processing have given us the ability to include National Marine Electronics Association (NMEA) navigation and the ability to compare expendable bathythermograph (XBT) profiles with CTD data. Enhancements in the sound velocity profile generator (SVPG) program will enable us to fully process moving vessel profiler data for inclusion into ISS60. Real-time communications allow us to transmit PhysO data from our

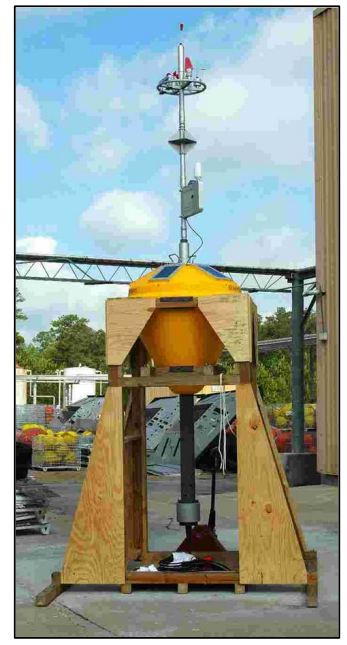

Fig. 7 Coastal Monitoring Buoy 
fleet of T-AGS back to our Survey Operations Center (SOC) and with Iridium capabilities, command and controls and real-time data transmission have allowed long-term autonomous glider deployments.

Our system of quality control and assimilation of satellite altimetry and sea surface temperature observations into operational oceanographic models has continued to progress and became more efficient. The manuallyintensive, cumbersome data retrieval, ingest, quality control, and assimilation of satellite altimetry data into the Altimetry Data Fusion Center (ADFC) has been replaced by a completely automated (24 hours a day, 365 days a year) satellite altimetry data assimilation process. The ADFC utilizes multiple network capabilities including the Committee for Operational Processing Centers and the Defense Asynchronous Transfer ModesUnclassified, which provide monitoring and multi-agency support. The

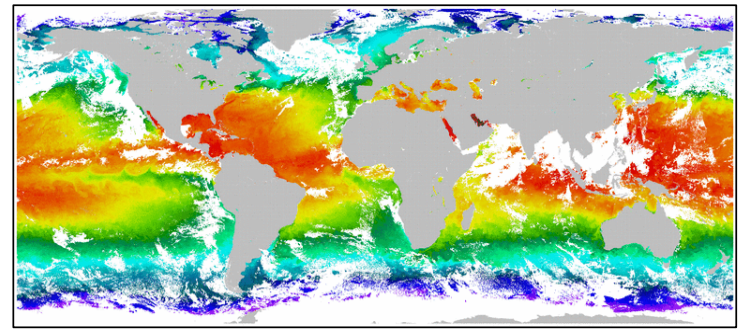

Fig. 8 NAVOCEANO daily coverage of 27 million satellite SST retrievals produced in near-real-time from GOES-East, GOES-West, NOAA-18, NOAA-19, and MetOp-A

ADFC has leveraged round-the-clock support from NAVOCEANO's computer operations staff for verification of data receipt, ingest, and product generation/distribution. Quality control capability has improved exponentially. Enhanced processing applications for Sea Surface Height Anomaly have included, along track interpolation/validation between records, crossover track comparison/ validation, and mesoscale and large-scale comparison. Wind/wave processing has been streamlined and enhanced to reduce data latency and improve product timeliness. Statistical and visual quality control/quality assurance functionalities are now embedded in product verification and validation.

The Multi-Channel Sea Surface Temperature (MCSST) program has increased the number of near-real-time satellite SST retrievals it is providing to NAVOCEANO ocean and Fleet Numerical Meteorology and Oceanography Center meteorological (METOC) models from 300,000 per day in 1998 to 27 million per day in 2010. Through work with international partners an additional 25 million SST retrievals per day are also acquired and provided to the METOC models. We have gone from processing data from a single satellite to processing data from eight satellites. During this time the quality and resolution of the data provided has increased to keep up with the demands of the operational METOC community. Some of the advances that made these improvements possible include re-hosting MCSST software three separate times to more powerful and efficient systems, rewriting code to enhance cloud detection and to add error statistics to each retrieval, improving communications for acquiring satellite data, and increasing SST generation in the littoral.

\section{F. Acoustics}

Acoustics shows a departure from the 2010 vision, primarily due to financial, data acquisition, and measurement constraints. Acoustic backscatter and reverberation data collection were reduced considerably. The early focus was instead to improve our standard data collection capability, take advantage of acoustic data already collected by others, and create an Anti-Submarine Warfare (ASW) Reach Back Cell (RBC) to fuse the many types of environmental data into useful products for our Fleet customers. In recent years, funding has been made available to invigorate bottom and volume scattering and loss measurement programs in association with the Navy's national laboratory partners. Intentions are to employ NAVOCEANO acoustic data in new ways, take advantage of acoustic data not traditionally used, as well as Fleet through-the-sensor data collections to improve bottom loss and backscatter information. Also, increased funding and improved collaboration with our partners has invigorated our characterization of ambient noise, improved databases, and through the ASW RBC, improved decision making processes for the Fleet.

Near-real-time transmission of acoustic transmission loss data from a T-AGS to the Survey Operations Center was executed in support of the TASWEX exercise in 2004. The data were processed, inverted, and used to upgrade an unofficial temporary version of our Low Frequency Bottom Loss database (LFBL) within a week. This temporary LFBL was used at NAVOCEANO and in some Fleet units during the exercise. During this exercise, the Satellite Telemetry Acoustic Recording System (STARS) buoy was used for the first time to measure and transmit ambient noise measurements in near real time.

The collection of transmission loss data utilizing T-AGS has continued with significant engineering advancements in data collection capabilities. A new Automated Acoustic Sensor, fondly referred to as "Buoy-zilla," has replaced the XN5 expendable sonobuoys, which required modification to make them suitable for broadband acoustic data collection. The result is a much improved data quality coupled with a greater range capability over that of the older buoys. Another significant improvement came with the addition of the hull-mounted SBP-120 sonar, a shallow penetration sub-bottom profiler that has proven to be a viable and efficient replacement for the towed CHIRP sonar sensor.

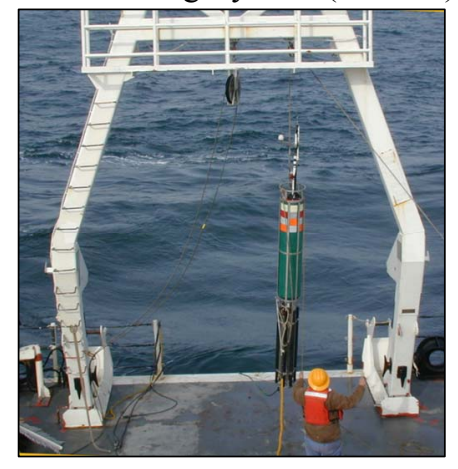

Fig. 9 Deploying Buoy-zilla from T-AGS vessel 
In the late 2000s, work with Space and Naval Warfare Systems Command (SPAWAR), the Applied Physics Laboratory at the University of Washington (APL-UW), and others began on the use of AUVs (gliders) for acoustic data collection. The APL-UW effort was a concept of operations experiment, testing glider deployment and recovery, transmission loss data collection, and data processing during an acoustic survey. While experiment goals were accomplished, it has not been determined exactly how such data can be effectively used to augment NAVOCEANO transmission loss surveys. The SPAWAR effort employs a glider to collect bottom loss measurements using ambient noise sources. We have participated in one experiment and intend to test glider deployment and recovery and bottom loss data collection and data processing from a T-AGS later this year. We are also looking at other longlasting AUVs which may perform similar functions.

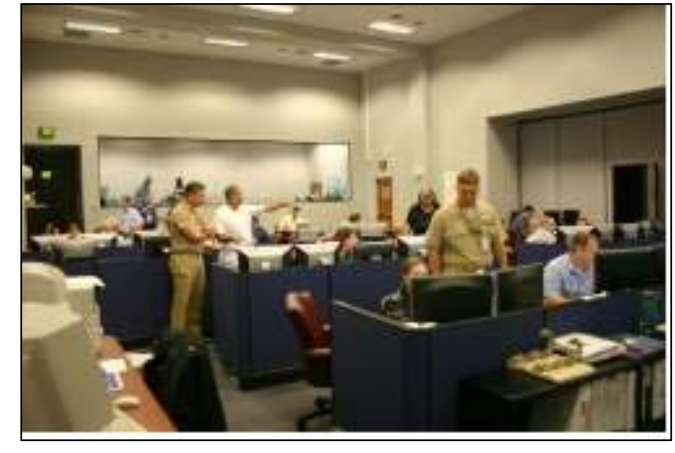

Fig. 10 ASW Reach Back Cell

Significant efforts have been put toward data fusion and real-time support to the Fleet. Real-time data ingest, data processing, databasing, and Fleet distribution have resulted in the use of new data sources, quantitative and qualitative improvements in the Ambient Noise database, and incorporation of new tools to provide Fleet support. Real-time data assimilation and fusion processes have been perfected over the course of several Fleet exercises, including TASWEX04, RIMPAC06, and VALIANT SHIELD 07. We now maintain a 14/7 watch of civilian acousticians as part of the ASW Reach Back Cell for real-time support to the Fleet. These civilians work with oceanographic and military counterparts to fuse environmental information, sonar performance estimates, and tactical information into products to aid the decision making process for the Fleet.

\section{G. Other}

The Mine Warfare organization (MIW) and Fleet Survey Team were not separate entities in 1998 and were not looked at individually. Both have made great strides in incorporating new survey technology, further increasing capability and capacity at NAVOCEANO. MIW has also focused on improving and automating the processing and quality control of the collected data to provide better information for their Fleet customers including the Naval Oceanography Mine Warfare Center (NOMWC), the operational arm of MIW in the METOC community. The improved software and methodology are used in-house as well as onscene during MIW exercises or operations by NAVOCEANO and NOMWC to analyze data collected from unmanned underwater vehicles (UUVs) equipped with both traditional side scan sonar systems and emerging technology such as synthetic aperture sonar. Future enhancements include positioning systems with interferometric side scan sonar for improved object detection and geolocation. Additional systems will include sub-bottom profilers onboard UUVs for improved detection of buried objects.

Additional new survey technology that is currently being explored includes various types of autonomous vehicles, expendable tide gages deployed from aircraft (further reducing our force protection footprint), and real-time data transfer from HSLs (potentially reducing manning). A new dynamic positioning system for the ships will provide for fuel efficiencies for both survey and routine vessel operations.

\section{CONCLUSION}

NAVOCEANO continues to push the envelope on efficient data collection - while simultaneously keeping an eye on the downstream information required by Fleet decision-makers. All in all, there is nearly an $80 \%$ correlation between the capabilities envisioned for 2010 and those actually employed at NAVOCEANO in 2010. In most cases, we've incorporated more than what was envisioned. We can be quite proud of the technological advances that have been incorporated in our survey efforts to support naval operations - i.e., the "smart collection" of NAVOCEANO's Vision statement - and the emphasis put on the follow-on "focused analysis" and "responsive delivery" - not only those envisioned 12 years ago, but staying on the cutting-edge of technology that helps us do our job better, faster, and cheaper.

\section{REFERENCES}

[1] D. McCarren, B. Reed, D. Johanson, M. Carron, B. Rankin, R. Wahl, B. Pope, G. Smith, T. Duvieilh, D. Bates, P. Taylor, and L. McCosh, "Survey 2010 A NAVO Vision," unpublished, Naval Oceanographic Office, 1998.

[2] CAPT Larry Warrenfeltz and CDR David McCarren, "Naval Oceanographic Office Ocean Survey 2010," Ocean Community Conference '98, November 1998.

\section{DISCLAIMER}

The inclusion of names of any specific commercial product, commodity, or service in this paper is for information purposes only and does not imply the endorsement by the U.S. Navy or NAVOCEANO. 